\title{
Factors affecting the clinical education of rehabilitation students in Iran: A systematic review
}

\author{
Marzieh Pashmdarfard ${ }^{1}$, Narges Shafaroodi ${ }^{* 1}$
}

\begin{abstract}
Background: Clinical education is one of the main parts in medical education, and rehabilitation sciences are not exception. Through clinical education programs, students gain required qualifications to enter professional life. Several factors impact on students' clinical education, and identifying these factors could help in the improvement of clinical education and could improve knowledge transferring to clinical practice especially in rehabilitation sciences in Iran. The purpose of present review study is identifying the factors potentially affecting the clinical education of rehabilitation students in Iran.

Methods: A systematic review study conducted based on the evidence-based method on published articles from 2000 to 2017 . The search process was carried out on MEDLINE, CINAHL, PsycINFO, and EMBASE databases.

Results: A total of 167 papers were selected. Given identical findings and considering eligibility criteria, 12 articles in the fields of clinical education, clinical competence, professional ethics education, and clinical reasoning were ultimately chosen.

Conclusion: The results indicate that many factors might influence the clinical education of rehabilitation science students. Environmental factors (including ministry policies, educational curriculums, clinical education environments, and educational facilities/equipment) and individual factors (the knowledge and skills of students and characteristics of clinical trainers) were identified as the most influential factors in clinical education.
\end{abstract}

Keywords: Education, Rehabilitation, Clinical competence, Professional practice, Students

Conflicts of Interest: None declared

Funding: None

*This work has been published underCC BY-NC-SA 1.0 license.

Copyright $₫$ Iran University of Medical Sciences

Cite this article as: Pashmdarfard M, Shafaroodi N. Factors affecting the clinical education of rehabilitation students in Iran: A systematic review. Med J Islam Repub Iran. 2018 (18 Nov);32:114. https://doi.org/10.14196/mjiri.32.114

\section{Introduction}

Clinical education is one of the most important concepts in health sciences and is an important bridge between educational environment and professional environment. During clinical education, students acquire a wide range of knowledge, skills and the clinical competence (1). Field work is an integral part of clinical education programs developed for health professionals, including rehabilitation specialists, which are essential to transfer theoretical

Corresponding author: Dr Narges Shafaroodi, shafarodi.n@iums.ac.ir

1. Department of Occupational Therapy, School of Rehabilitation Sciences, Iran University of Medical Sciences, Tehran, Iran knowledgefrom an academic setting into practice in reallife settings $(2,3)$. Clinical education is defined as the acquisition of professional skills by putting knowledge into practice in real-life situations under supervision or by using a clinical-educational model. Some health professionals consider learning through clinical education as the result of active participation of learners, while others regard the level of students' knowledge and ability as an

$\uparrow$ What is "already known" in this topic:

Clinical education is one of the most important concepts in medical education especially in rehabilitation sciences. The main factors which influence clinical education should be identify to promote the professional competency of student.

$\rightarrow$ What this article adds:

Environmental factors (including ministry policies, educational curriculums, clinical education environments, and educational facilities/equipment) and individual factors (the knowledge and skills of students and clinical education trainers' characteristics) are among the main factors influencing the clinical education of rehabilitation students. 
influential learning factor. In another definition of clinical education, trainers' ability to transfer their skills, ideas, and beliefs regarding the way students should deal with patients is highlighted. Based on this definition, the critical role of trainers is underscored as one of the major factors influencing clinical education (4). Clinical education can be effective and useful if it enhances new learning, develops clinical reasoning and critical thinking, promotes a sense of responsibility in students, develops cultural competence, and provides better planning and more proper ways of implementing rehabilitation interventions (5, 6). The knowledge acquired in educational environments is a unique experience, and has a crucial role in shaping required practical skills and enhancing professional capabilities of students (7). From a historical point of view, clinical education proves its commitment to the philosophy of professional education in terms of both theory and practice. John Dewey believes that professional performance in the real world depends on the particular subjective analysis and on the interpretation of new situations. (8). Clinical education improves students' clinical competence through providing greater opportunities to gain educational experiences. Over the course of clinical education, using active learning in which students, trainers, and patients are able to interact with each other collaboratively, educational trainers can enhance students' empirical learning, clinical reasoning, and reflection (9). The initial step in developing professional skills is to acquire theoretical knowledge which can be obtained in classroom settings, the purpose of this knowledge acquisition is to put it into practice in clinical settings in which the focus is on applying knowledge under supervised interventions during clinical practice and on the critical role of patients, families, specialists, and other important people. Students should demonstrate their professional values and beliefs based on ethical principles while doing their clinical practice (10). Due to the importance of clinical education and assessment in the transfer and generalization of theoretical concepts to clinical practice in clinical settings, educational centers have attempted to have graduates with high levels of clinical competence via reconsidering everything based on a wide variety of research-based reviews. Considering the fact that rehabilitation programs in Iran are new and still developing, educational needs are changing very fast; as a result, rehabilitation specialists face a variety of educational challenges (10). Since clinical education plays an important role in students' post-graduate clinical practice, the evaluation of educational services helps improving the quality of educational activities and the development of learners' skills (11). In order to improve the quality of clinical education, rehabilitation specialists need to know the factors influencing clinical education. In Iran, few studies were conducted on the field of medical education, especially rehabilitation sciences. This study aims to review and extract the main factors influencing the clinical education of rehabilitation science students in Iran.

\section{Review of the literatures}

A systematic evidence-based review process, which was developed by Duffy et al in 2005, was used (12). The reporting of the study is according to the Preferred Reporting Items for Systematic Reviews and Meta-Analyses (PRISMA) reporting guidelines for systematic review studies (13).

\section{Search Strategy}

All Persian and English language articles on the clinical education in rehabilitation sciences in Iran, from 2000 to 2017 were used. MEDLINE, CINAHL, PsycINFO, and EMBASE databases were systematically searched for studies on clinical education in rehabilitation sciences in Iran. The key words which were used in the process of search were clinical education, occupational therapy, physical Therapy, optometry, auditory, speech Therapy, technical orthopedic, rehabilitation, and the Boolean operators AND, OR, were used to combine these terms together for example; clinical education AND occupational therapy.

\section{Inclusion and exclusion criteria}

The inclusion criteria were research studies on clinical education in rehabilitation sciences. All retrospective and prospective articles, experimental and semi-experimental studies, observational studies, qualitative studies which conducted in Iran have entered in this study. And those articles which weren't in the clinical education of rehabilitation sciences field were removed from study (Table 1).

\section{Results}

In the process of search two independent researchers, one of them familiar with the concept of clinical education and medical sciences and the other not familiar with medical education at all, searched the articles based on key words and data base resource individually. After pooling the articles, the rate of agreement between two researchers was approximately $80 \%$. The full text and abstract of the articles were collected for the study. Total of 363 articles found, 196 of the articles removed because of duplication, 100 of those article removed too because they weren't directly related to the clinical education of rehabilitation sciences and theremain 67 articles were screened again, 27 of the 67 articles had eligibility criteria for the study. After deep reviewing of those 27 articles, 15 of them were removed too because, they weren't directly related to clini- 


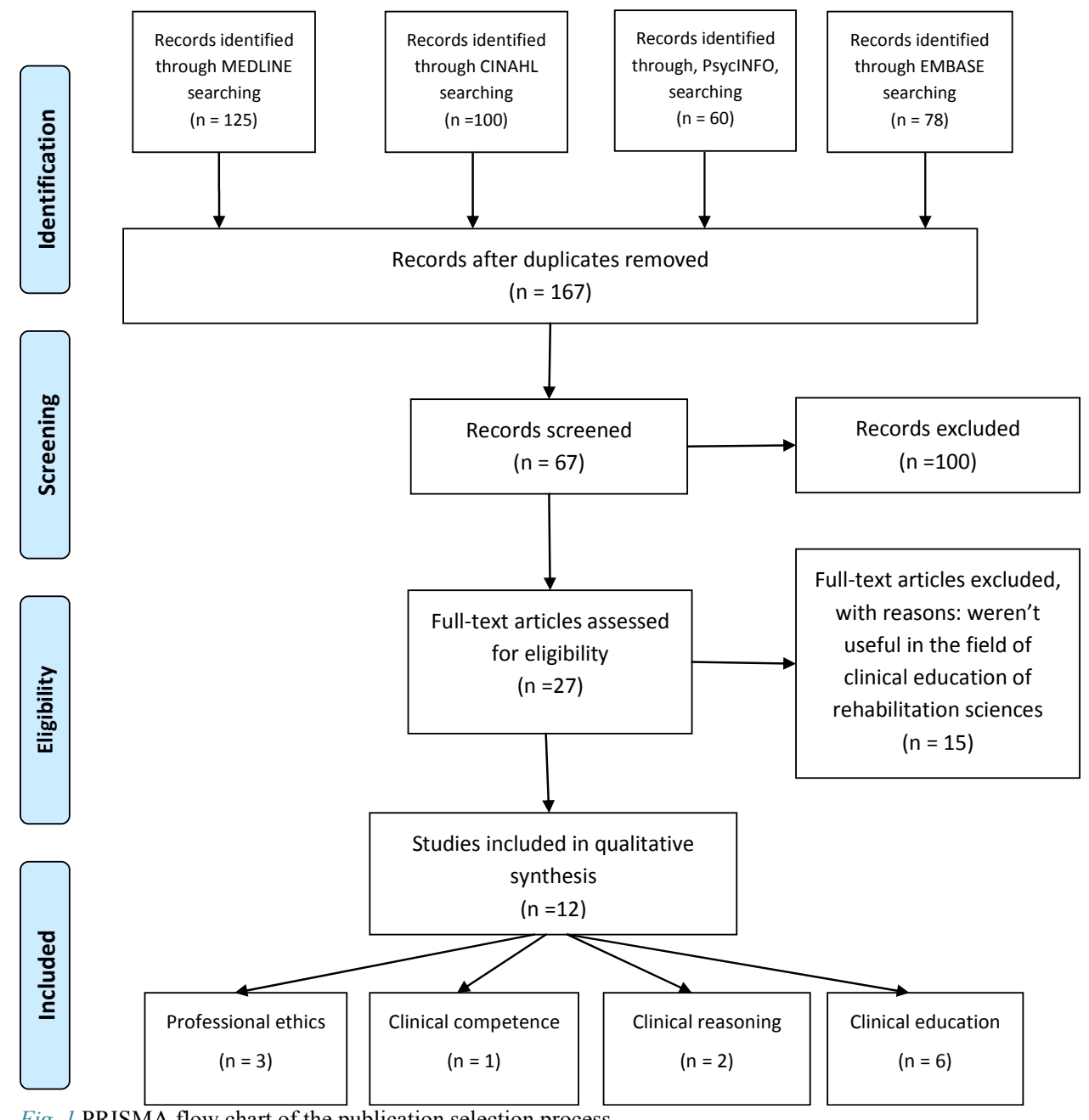

Fig. 1.PRISMA flow chart of the publication selection process

cal educations and they were the kind of study which they generalized their results to clinical education and finally the 12 articles included in this study (Fig. 1). The findings of each study were categorized in Table 2.

Discussion

Table 2.The results of the review articles

\begin{tabular}{|c|c|c|c|c|c|c|c|c|}
\hline & $\begin{array}{c}\text { Number of } \\
\text { articles }\end{array}$ & Authors & Title & Year & Type of study & $\begin{array}{c}\text { Sample } \\
\text { size }\end{array}$ & Samples & Results \\
\hline 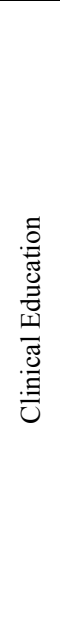 & 6 & $\begin{array}{c}\text { Rezaee M } \\
\text { et al(10) }\end{array}$ & $\begin{array}{l}\text { Explaining the } \\
\text { process of clinical } \\
\text { education in } \\
\text { occupational } \\
\text { therapy }\end{array}$ & 2014 & $\begin{array}{l}\text { Qualitative } \\
\text { through the } \\
\text { grounded } \\
\text { theory Method }\end{array}$ & 31 & $\begin{array}{c}18 \text { students, } 13 \\
\text { managers and } \\
\text { instructions, and } 3 \\
\text { graduated of } \\
\text { occupational } \\
\text { therapy }\end{array}$ & $\begin{array}{l}\text { Transcribed data were } \\
\text { results to } 1556 \text { open } \\
\text { codes which were cate- } \\
\text { gorized to five main } \\
\text { categories: multiple } \\
\text { performances of instruc- } \\
\text { tors, wandering of stu- } \\
\text { dent among different } \\
\text { experience, insufficient } \\
\text { management and plan- } \\
\text { ning, distress in the } \\
\text { learning struc- } \\
\text { ture/atmosphere and } \\
\text { instability in entering } \\
\text { the professional world. } \\
\text { The most abstract con- } \\
\text { cept emergent in data } \\
\text { was 'the lack of unite } \\
\text { pattern' and it related to } \\
\text { other categories. }\end{array}$ \\
\hline
\end{tabular}




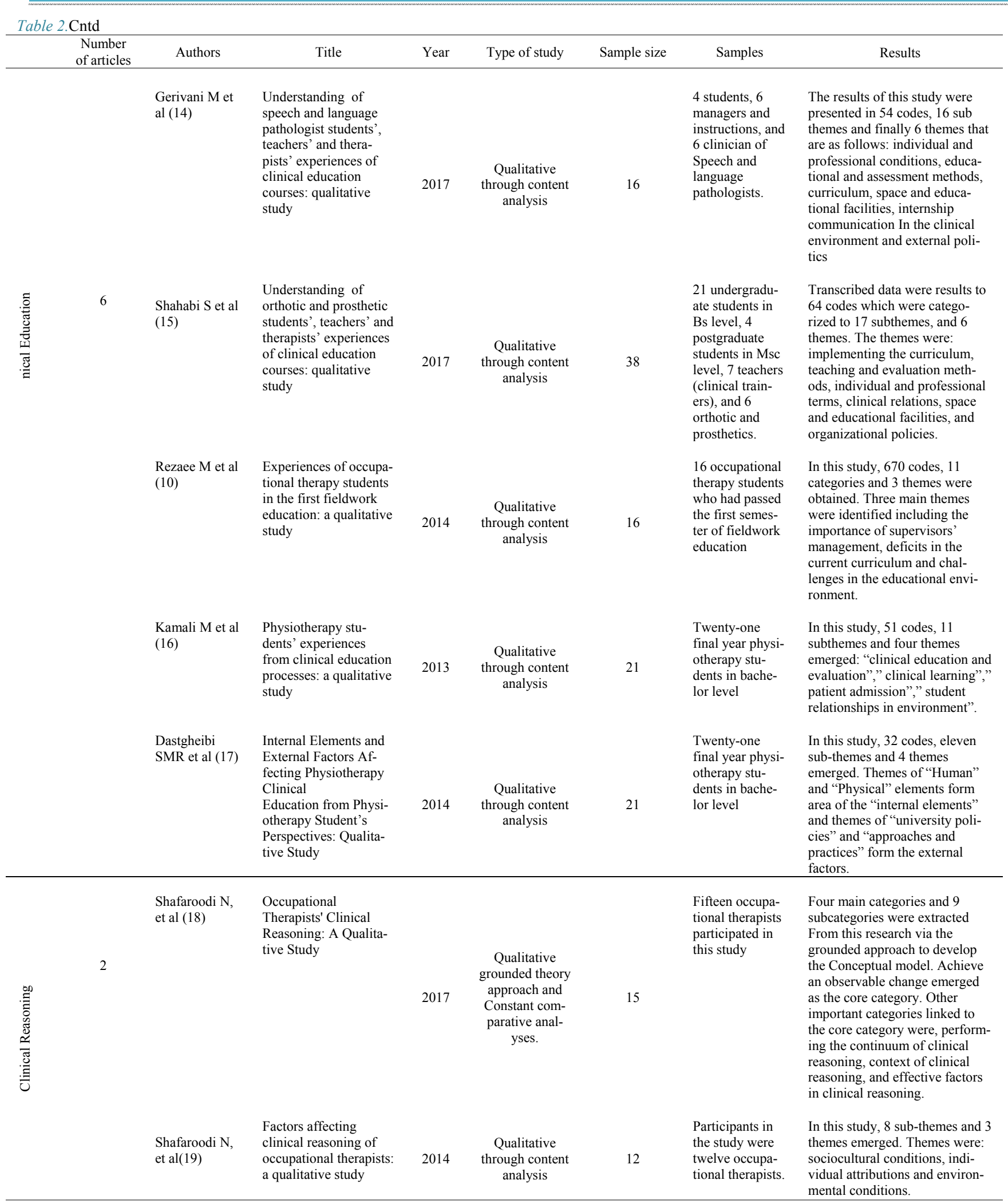

This study aimed to distinguish and review the influential factors in the clinical education of rehabilitation science students in Iran. The educational officials take trainers' and students' perspective into account so identifying the influential factors in clinical education. This information helps to improve students' clinical competence and experiences. In this review study, individual factors (i.e., students' and trainers' characteristics) and environmental factors (i.e., ministry policies, educational environments, educational equipment and facilities, and educational curriculums) were identified as influential factors affecting students' clinical education (Table 3). Being aware of each of these factors, rehabilitation specialists, especially those who work in the field of education, are able to enhance the 


\begin{tabular}{|c|c|c|c|c|c|c|c|c|}
\hline 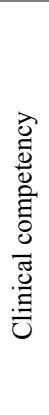 & 1 & $\begin{array}{c}\text { Zamani- } \\
\text { anJahromi S, } \\
\text { at al (20) }\end{array}$ & $\begin{array}{l}\text { Compiling the Clinical } \\
\text { Competence of Occu- } \\
\text { pational therapists' } \\
\text { perspective (Content } \\
\text { Analysis) }\end{array}$ & 2017 & $\begin{array}{c}\text { Qualitative } \\
\text { through } \\
\text { content } \\
\text { analysis }\end{array}$ & 13 & $\begin{array}{l}\text { The participants included } \\
13 \text { occupational thera- } \\
\text { pists with at least } 2 \text { years } \\
\text { of clinical experience. }\end{array}$ & $\begin{array}{l}\text { The result of this study includes } \\
\text { the two main categories of } \\
\text { "clinical competence" and } \\
\text { "factors influencing clinical } \\
\text { competency. "Clinical compe- } \\
\text { tencies include } 2 \text { subcategories } \\
\text { of "commitment" and "skill" } \\
\text { and factors influencing clinical } \\
\text { competency including three } \\
\text { subcategories of "Supportive } \\
\text { Educational Supervisory } \\
\text { system", "social factors" and } \\
\text { "individual factors". }\end{array}$ \\
\hline
\end{tabular}

10 Iranian occupational therapists, Two of the occupational therapists were $\mathrm{PhD}$ students, three of them had

master's degrees, and the remaining five had Bachelor's degrees in occupational therapy. All participants had between 6 and 25 years of experience in working with children
The main categories of ethical practice when working with children included personal attributes, responsibility toward clients, and professional responsibility, which consisting of 13 subcategories, Personal attributes included four subcategories: veracity, altruism, empathy, and competence. Responsibility toward clients consisted of six subcategories: equality, autonomy, and respect for clients, confidentiality, beneficence, and nonmaleficence. Professional responsibility included three subcategories: fidelity, development of professional knowledge, and promotion and growth of the profession.

Participants included 12 (5 Male and 7 female) occupational therapists, with a work experience of 5 to 25 years, Five participants held BS degree, 3 MS degree and 4 were PhD students.

10 graduated occupational therapists with at least two years' experience were participated in

Occupational thera-

Vahidi $\mathrm{H}$ et pists' perception of al (23)
The factors influencing ethical behavior were classified into 12 subcategories and four main categories including Organizational factors, therafamily issues, and social factors.

Data analysis showed that unethical practice of occupational therapists in the physical dysfunction field categorized in four categories. These categories include: deviation of treatment, neglect of client benefits, disregarding of communication principles and emphasis on financial benefits. pist related factors, client's unethical practice in adults' physical dysfunction field
Qualitative
through
content
analysis course of the clinical education of students, especially rehabilitation science students.

Regarding the importance of clinical skills, Jahromi et al. (2005) declare that universities are required to educate students in such a way that they gain the required ability to prevent, treat, and promote health in the community (23). After achieving required theoretical knowledge in classroom settings, students need to gain their practical abilities through their real-life practices and experiences in clinical settings. However, numerous studies reported a gap between theory and practice in clinics $(23,24)$. Over the course of education, teaching and learning are interdependent, although teaching is what trainers do; but the

way of teaching is so important because it leads to learning of students (25). The findings of the present study proved the gap between theoretical education and clinical training in rehabilitation sciences. Most of the reviewed studies showed that the students couldn't apply the learned theoretical courses in clinical practice (10) if the factors affecting the quality of education in rehabilitation sciences are well identified, educational specialists can make required changes in educational processes and promote these processes by considering these influential factors. In a similar vein, Johnson et al. (2006) came to the same conclusion and reported a gap between theory and practice. In their study, they declared that problems arose 
Table 3. Themes of studies

Themes of studie

Common themes

Merged themes

1 Multiple performances of instructors, wandering of student among different experience, insufficient management and planning, distress in the learning structure/atmosphere, instability in entering the professional world.

2 individual and professional conditions, educational and assessment methods, curriculum, space and educational facilities, internship communication In the clinical environment, external politics

3 Implementing the curriculum, teaching and evaluation methods, individual and professional terms, clinical relations, space and educational facilities, organizational policies.

4 Supervisors' management, deficits in the current curriculum, challenges in the educational environment.

5 clinical education and evaluation, clinical learning, patient admission, student relationships in environment

6 Human elements, Physical elements, university policies, approaches and practices.

7 Performing the continuum of clinical reasoning, context of clinical reasoning, and effective factors in clinical reasoning.

8 Sociocultural conditions, individual attributions, environmental conditions.

9 clinical competence, factors influencing clinical competency

10 personal attributes, responsibility toward clients, professional responsibility

11 Organizational factors, therapist related factors, client's family issues, social factors.

12 Deviation of treatment, neglect of client benefits, disregarding of communication principles, emphasis on financial benefits.

when it came to the transfer of theoretical knowledge into clinical practice, and there was a gap between what was learned in the classrooms and what was actually needed in clinical settings they can't use the theoretical knowledge properly in clinical setting $(26,10)$. They showed that various influential environmental and individual factors were involved. Similarly, in the current review study, the results verified the influence of numerous factors on the clinical education of rehabilitation science students and on the knowledge transfer from theory to practice. Although education processes, in particular clinical education, are different among various fields of study, the findings of this study showed that they have a lot in common regarding educational needs, especially the clinical education needs of rehabilitation sciences students, and with respect to some concepts. In all of these studies, educational environments, educational curriculums, as well as experienced and competent trainers are identified as common themes which have the potential to exert an influence on the knowledge transfer from theoretical concepts to clinical practice. The results of various studies conducted on clinical education in nursing have also confirmed the gap between theoretical education and clinical education (23). The results of these studies indicate that socio-cultural environment, the structure of curriculums, ministry policies, the clinical competence of trainers, and educational centers are among the factors generating this gap (24). In 2005, Zareiyan et al. introduced environmental and social facilities as sources of motivation for nursing students to learn more, especially with regard to clinical practice (23). The findings of the current study also revealed that educational environments were one of the important factors that exerted an influence on clinical education. In 2006, Abdi et al. concluded that the lack of educational centers, educational environments, and educational equipment and facilities were among the influential factors in trainers' choosing traditional methods (supervisory method) of clinical education. In their study, they declared that rehabilitation trainers utilized traditional methods in their clinical education to compensate for the drawbacks caused by the lack of educational centers (27). When educational needs and challenges are emerging and changing all the time, the use of traditional methods in clinical education would result in students' incompetency in clinical practice. Therefore, the consideration of clinical environments as one of the most important factors impacting on students' future occupation can improve the clinical education and clinical competence of students. In 2016, SeyyedHabibi, et al. carried out a study to explain the physiotherapists' perception of Evidence-Based Practices (EBP), in their study they found that the experience gained by the therapists and the clinical education received by them during their training were two significant factors influencing the physiotherapists' perception of evidence-based interventions (28). Based on the philosophy of EBP which is "doing the right things right" it can be stated that using the evidence based interventions by therapists needs the learning which carried out in clinical setting by trainers and their experience. In numerous studies, trainers are considered as one of the most significant and facilitative factors in clinical education, which can develop the clinical competence of students considerably (12, 26, 28 and 29). In 2007, Thomas, et al. showed that due to the absence of training, educational programs, and curriculums, trainers used different educational and supervisory methods in clinics, which, in turn, resulted in students' being under stress and experiencing duality while they performed clinical practices (25). In 2003, Landmark et al. considered trainers' competence as a factor influencing nursing students' acquisition of clinical skills (24). To this end, educational systems should emphasize the role of trainers as one of the factors promoting clinical competence of students, and educational groups should underscore the role of trainers in their training curriculum more. To maximize clinical competence of students, it is essential to minimizing the gap between theoretical knowledge and clinical practice. In order to acquire the satisfactory clinical competence, numerous factors are involved; however, trainers play a primary role in the process of clinical education (10). In order to have proper clinical training, first of all, educational trainers need to have good clinical qualifications. In in other countries, concepts such as the absence 
of competent trainers, the lack of coordination among clinical training, and the lack of facilities (i.e., clinical education environments) are considered as the problems of clinical education from the viewpoint of students and clinical trainers $(24,26,30$ and31). In 2014, Dadgostarnia et al. studied the effect of workshops on increasing the knowledge and readiness of medical students before their internships. Holding pre-internship workshops influenced on the knowledge transfer from theoretical concepts into clinical practice (32). Improved educational policies in clinical education couldimpact of environmental and educational facilities, trainers' expertise, and better educational curriculums on diminishing the gap between theory and practice. One of the main problems which is related to the policy of Ministry of Health and Medical Education is that, the rehabilitation sciences in Iran is still considered as a basic sciences rather than a clinical sciences. By taking into account the individual and environmental factors influencing clinical education, rehabilitation specialists could promote the knowledge transfer from theoretical concepts into clinical practice and improve the clinical competence of students.

\section{Conclusion}

The review of various studies indicated that clinical education could influence many factors, such as professional ethics, motivation, clinical competence, evidence based practice, and individual and environmental factors in rehabilitation sciences. By identification of these factors and promotion of clinical education, the factors influenced by clinical education, including the clinical competence of students and therapists can be enhanced. All of the environmental factors (ministry policies, educational curriculums, and clinical education environments and facilities) and individual factors (students' knowledge and skills, clinical education trainers' efficiency and characteristics) affect clinical education. By improving each of the abovementioned factors and overcoming obstacles to each factor, it is possible to achieve desirable clinical education, and consequently assist students to acquire satisfactory levels of clinical competence.

\section{Suggestions}

Given that numerous factors influence the clinical education of rehabilitation science students, it is suggested that by conducting a mixed method study, the barriers of clinical education of rehabilitation sciences be detected and appropriate educational strategies be developed.

\section{Conflict of Interests}

The authors declare no conflict of interests.

\section{References}

1. Hirneth M, Mackenzie L. The Practice Education of Occupational Therapy Students with Disabilities: Practice Educators' Perspective. Br J Occup Ther. 2004;67(9):396-403.

2. Sevenhuysen SL,Haines T. The slave of duty: Why clinical educators across the continuum of care provide clinical education in physiotherapy. Hong Kong Physiother J. 2011;29(2):64-70.

3. Higgs J, Mcallister L. Being a clinical educator. Advances in health science education. 2007;12(2):4.

4. DeClute J, Ladyshewsky R. enhancing clinical competence using a collaborative clinical educational model. Physic Ther. 1993;73(10):683-9.

5. Dastgheibi SMR, Kamali M, Dadgoo M, Chabok A. Internal Elements and External Factors Affecting Physiotherapy Clinical Education from Physiotherapy Student's Perspectives: Qualitative Study. J Res Rehabil Sci. 2014;10(3):393-407.

6. Murden R, Norman A, Ross J, Sturdivant E, Kedia M, Shah S.occupational therapy student's perceptions of their cultural awareness and competency. Occup Ther Int. 2008;15(3):191-203.

7. Cohn ES. fieldwork education shaping the foundation of clinical for clinical reasoning. Am J Occup Ther. 1989;43(4):240-4.

8. Ghamari N, Shafaroodi N, Derakhshanrad SAR, Ghamari M, Ghamari E. Motivational needs and its relationship with motivation potential in occupational therapy profession. $\mathrm{J}$ Rehab Med. 2015;3(4):62-72.

9. Vahidi H, Shafaroodi N, Joolaee S. Occupational therapists' perception of unethical practice in adults' physical dysfunction field. J Rehab Med. 2015;4(2):70-78.

10. Rezaee M, Rassafiani M, Khankeh H, Hosseini SA. Experiences of occupational therapy students in the first fieldwork education: a qualitative study. Med J Islam Repub Iran. 2014;28:110-5.

11. Haynes DA. Philosophy of occupational therapy education. Am J Occup Ther. 2007;61(6):678.

12. Law M McDermid J. Evidence-based rehabilitation: A guide to practice. Slack Incorporated. 2008:143-7.

13. Moher D, Liberati A, Tetzlaff J, Altman DG. PRISMA Group. Preferred reporting items for systematic reviews and meta-analyses: the PRISMA statement. PLoS Med. 2009 Jul 21;6(7):1-6.

14. Gerivani H. Understanding of speech and language pathologist students', teachers' and therapists' experiences of clinical education courses: qualitative study. Speech Lang Hear. 2018; 21(3):132-141.

15. Shahabi S, Kamali M. Understanding of orthotic and prosthetic students', teachers' and therapists' experiences of clinical education courses: qualitative study, 2017. EC Orthopaedics. 2017;6(6):230237.

16. kamali M, Dastgheibi SMR, Chabok A, Dadgoo M, Ghanaatian S. Physiotherapy students' experiences from clinical education processes: a qualitative study. J Res Rehabil Sci. 2013;9(5):818-832.

17. Dastgheibi SMR, Kamali M, Dadgoo M, Chabok A. Internal Elements and External Factors Affecting Physiotherapy Clinical Education from Physiotherapy Student's Perspectives: Qualitative Study. J Res Rehabil Sci. 2014;10(3):393-407.

18. Shafaroodi N, Kamali M, Parvizi S, Hassani Mehraban A. Occupational Therapists' Clinical Reasoning: A Qualitative Study. Iran Rehabil J. 2017;15(3):277-286.

19. Shafaroodi N, Kamali M, Parvizy S, Hassani Mehraban A, O’Toole G. Factors affecting clinical reasoning of occupational therapists: a qualitative study. Med J Islam Repub Iran. 2014;28:8.

20. Zamanian Jahromi S, Shafaroodi N, Lajevardi L. The Skills Required for Clinical Competence: Qualitative Research. J Rehab Med. 2018;7(2):83-89.

21. Kalantari M, Kamali M, Joolaee S, Rassafiani M, Shafarodi N. Perception of professional ethics by Iranian occupational therapists working with children. J Med Ethics Hist Med. 2015;8:1-8.

22. Kalantari M, Kamali M, Joolaee S, Shafarodi N, Rassafiani M. Factors affecting ethical behavior in pediatric occupational therapy: A qualitative study. Med J Islam Repub Iran. 2015;29:282-289.

23. Zareiyan Jahromi A, Ahmadi F. Learning Needs Assessment in Bachelor of Nursing: a Qualitative Research. Iran J Med Educ. 2005; 5(2):81-92.

24. Nasiriani KH, Vanaki Z, Ahmadi F. Clinical Supervision in Rocky Roads. Hakim Res J. 2012;14(4):191-202.

25. Thomas Y. Benefits and challenges of supervising occupational therapy fieldwork students: supervisors' perspectives. Aust Occup Ther. 2007;54(4):2-12

26. JohnsonCR. Level I fieldwork today: a study of context and perceptions. Am J Occup Ther. 2006;60(3):275-287.

27. Abdi K, Ghanaatian Chabzari S, Khankeh H, Hosseini MA. Evaluation of educational situation of rehabilitation branches in welfare and rehabilitation university. Quart J Rehabil. 2006;7(4):6467.

28. Seyed Habibi S, Noorizadeh Dehkordi Sh, Dadgoo M, Lajevardi L. Physiotherapists' Perception of Evidence- Based Practice. J Modern 
Rehabil. 2016;10(4):169-176.

29. Salimi T, Khodayarian M, Rajabioun H, Alimandegari Z, Anticchi M, Javadi S, et al. A survey on viewpoints of nursing and midwifery students and their clinicalinstructors at 113 Faculty of Nursing and Midwifery of Shahid Sadoughi University of Medical Sciences towards clinical education during 2009-2011. J Med Educ Develop. 2012;7(3):67-78

30. Cheraghi MA, Salasli M,Ahmadi F. Iranian nurses' perceptions of theoretical knowledge transfer into clinical practice: A grounded theory approach. Nurs Health Sci. 2007;9(3):212-220.

31. Salsali M, Cheraghi MA, Ahmadi F.Organizational factors influencing knowledge transfer into clinical practice in Iranian nursing context: A rounded theory approach. Int J Nurs Pract. 2009;15(5):426-436.

32. Dadgostarnia M , Vafamehr V. Assessment of training needs of students' clinical skills prior to entering the clinical course and Impact of preliminary courses of training clinical skills on students. Iran J Med Educ. 2014;14(1):52-63. 